\title{
Effect of Seasonal Changes of the Electric Field Pattern in Ibadan Nigeria on Some Meteorological Parameters
}

\section{${ }^{1}$ ADETOYINBO, AA; ${ }^{2 *}$ BELLO, AK; ${ }^{1}$ AKINWALE, SA}

\author{
${ }^{1}$ Department of Physics, University of Ibadan, Nigeria \\ ${ }^{* 2}$ Department of Physical Sciences, Bells University of Technology, Ota, Nigeria \\ *Corresponding AuthorEmail-akbellokazeem@gmail.com;akbellokazeem@yahoo.com
}

\begin{abstract}
The objective of this work is to investigate the variation of the electric field in the atmosphere to specific meteorological parameters such as (temperature, heat and relative humidity) in Ibadan using data collected from the Nigeria Meteorological (NiMet) Office in Lagos. The data obtained were used to analyze the patterns of electric field in every season in this location for a period of one year ranged from September to October.
\end{abstract}

DOI: https://dx.doi.org/10.4314/jasem.v25i2.22

Copyright: Copyright $(C 2021$ Adetoyinbo et al. This is an open access article distributed under the Creative Commons Attribution License (CCL), which permits unrestricted use, distribution, and reproduction in any medium, provided the original work is properly cited.

Dates: Received: 12 December 2020; Revised: 26 January 2021; Accepted: 12 February 2021

Keywords: Electric Field, Relative Humidity, Temperature, Pressure, Wind, Polluted Aerosols

The Atmospheric electric fields are among the geosciences of geophysics which is very important and comprehensive research area. An essential parameter is the electric field Ambient for understanding Worldwide Ambient Electrical Circuit (WAEC). The area within the Earth's surface zone and the ionosphere comprises the global atmosphere's electric circuit. Both the atmosphere and the ionosphere are tough conductors of energy, whereas the air isn't a good conductor between these two, therefore the air works fairly just like an insulator. On the electric fields, the WAEC is majorly driven by lightnings, thunderstorms, electrified air and clouds of rain Wilson, (1920). The WAEC also influences energetically charged space objects Rycroft and Harrison (2011). There are many topics directly ties to the WAEC such as electrified clouds of rain, D.C. electric fields measurement, energy and electrical concentrations, mesoscale convective approaches, the unstable convective currents, earth ionosphere wave map, thunderstorms etc. During most of the 18th century, Benjamin Franklin's research on electrical properties in the thunderstorm opens a new era (age) in electrostatic study reported by Torns, (2006). Soon since Franklin's observation, work on ambient electric field of fair weather has begun, and continues till today. Fairweather situations are the ones where there are central processes of electrification and no substantial continuous cloud distribution Harrison, (2013). Electric fields calculated on the surface of the Earth are continuously recognized as the main sources of fact for atmospheric electric research, whether national, provincial or restricted, these measures would have a real mapping of the Ionosphere potential variation. Electric fields calculated on the surface of the Earth are continuously recognized as main sources of fact for atmospheric electric research, whether national, provincial or restricted. Potential of the same sheet, bound atmospheric conductivity and density of space charges near the ground decide the magnitude of the electric field of surface at any level. Many researchers have stated that various surface intensity of electric field measurement have been carried out in coastal, freshwater, polar and also in mountainous regions to investigate both the regional and international impact of electric field, among them is Harrison, (2013). Johnson et al., (2011) reported the formation of secondary particles through chemical transformation of gaseous substances. Many researchers that work on air pollution reported that all cases studied confirmed the released of emitted particulate matters directly from secondary processes. Some researchers have work on suspended particulate matter, among them are Ikamaise et al., (2013), they work on total suspended particulate matter in Calabar air basin, Moses and Orok (2015) studied suspended particulate matter in Uyo, Nigeria, while Ezeh et al., (2012) concluded their own study on PM10 and PM2.5 samples that was obtained in Ikoyi, Lagos, Nigeria. It could be believed that in the midst of various meteorological conditions, charged nuclei, atmospheric ions and their relations create local atmospheric portion of electric field. Based on the source, meteorological parameter impact on the 
variance in electric field is significant. Similar weather conditions occur for a significant period of time before naming a season. Moreover, 24th hours duration is the prevailing lunar cycle for any terrestrial electrical component. Therefore, the daily variation of electric field in diverse seasons is of paramount significance in the decision regarding electrical state. Some researchers among who are Bennett and Harrison (2006a) reported significant differences in mean atmospheric electric field values between fair weather and disturbed weather. There are period of consistency at which higher electric fields were measured in the month of winter and lesser values in the summer as reported by Retalis and Retalis (1997). Therefore, the objective of this work is to investigate the effect of seasonal changes of the electric field pattern in Ibadan Nigeria on specific meteorological parameters such as temperature, heat and relative humidity.

The Study Area: The study area is Ibadan. It is located on Latitude $7^{\circ} 39^{\prime}$ and Longitude $3^{\circ} 90^{\prime} \mathrm{E}$, situated in south-western Nigeria 128 kilometers $(80 \mathrm{mi})$ northeast of Lagos and 530 kilometers (330 mi) south-west of the Federal capital, Abuja, and is a popular transit point between the coastal region and the hinterland areas of the country.

Conduction current- It is the current in the conductor if the electromagnetic field stays fixed in time. Suppose E is changing constantly. In this situation, a displacement current $\left(I_{D}\right)$ is the current in the area $E$.

$$
I_{D}=\varepsilon_{0} \frac{d \emptyset_{E}}{d t}
$$

Conduction current consists of charged particles that travel in reaction to the electrical field and are not necessarily borne by the ambient fluid movement.

The vertical atmospheric electric field $E$ is by recorded as the potential gradient $\mathrm{F}$ in equation defined by the negative of electric field:

$$
\text { Where } \quad F=-E
$$

The air conductivity $\left(\sigma_{T}\right)$, potential gradient $(F)$ and conduction current density is related by Ohm's Law:

$$
F=\frac{J_{C}}{\sigma_{T}}
$$

Experimental Design, Materials and Methods: The atmospheric electric fields were daily observed using data collected from NiMet Office, Lagos. Three seasons were considered (Winter, Spring, Monsoon and Summer) to analyze the patterns of the electric field in every season in Ibadan for one year. In Nigeria the identified modern seasons are; Winter
(November, December, January, and February), Spring (March, April, May), Summer (June, July, August) and Autumn (September, October, November). An electrical field mill is a piece of equipment which measures the relative strength of the electrical field of the atmosphere and relies on electrostatic amplification as it consists of one or two electrodes. The Zebra field mill tag usually allows a detector used for this research. The field mill contains charged amplifiers that sense and convert charges on the plate into a voltage. There are two performance information types, an optical voltage screen which varies, measured numerically with electrical field and broadcasting of digital output. The electronic output is shown in the machine by means of Win-Mills which is based on Window field mill software. In a bit to find fair weather days, we used the Nigerian Meteorological Agency (Nimet) weather information. A few environmental metrics such as 2018/2019 years of rainfall, wind speed, cloud cover, etc. are favored. The atmosphere electric field frequency for this collection is $865-\mathbf{1 8 4} \mathbf{V} / \mathbf{m}$. A test frequency of $\mathrm{N}$ specimens per minute is used to measure atmospheric electric field values.

\section{RESULTS AND DISCUSSION}

The lowest number of days is seen in summer months as electrified storms are most frequent in the monsoon relative to the winter and are therefore more prone to disrupt fair weather. Figure 1: Daily variation of ground $(\mathrm{EF})$ : four seasons' (N.D.J.F. for winter, J.J.A.S. for monsoon (summer) and F.M.A.M. for spring) relationship. The highest value of the EF was observed in summer with the next higher value in the months of winter, the least value was observed in the spring. The atmosphere was more visible in the months of summer and less visible in the months of winter. The temperature was highest during in summer and higher in autumn with the least value observed during spring. The highest value of relative humidity was recorded during the months of winter and higher value in autumn while the least was recorded in the summer. The highest value of pressure was recorded in winter while those recorded in summer and autumn were close to each other and the least value was observed in spring. A likely explanation for this seasonal difference is likely to be the increase the concentration of aerosols close to the surface during winter because the lack of strong surface heating and deep convective mixing suggests that the emission produced at the surface is limited to 
the near surface where the electric fields are calculated and not stretch upwards by convective mixing during the summer. Human activities such as smokes discharges from Urban industrialization, carbon dioxide from burning gases, coal burning and also changes arise from the burning of fossil fuels e.t.c. also contribute to the variation in atmospheric electric field. Figure 2 is the Zebra Electric Field Mill Sensor that measured the atmospheric electric field.

Table 1: Mean values of daily variation of ground (EF): (for winter, monsoon and summer) and yearly average Time Summer Monsoon Winter Yearly

\begin{tabular}{lllll} 
(hrs) & $\left(\mathrm{Vm}^{-1}\right)$ & $\left(\mathrm{Vm}^{-1}\right)$ & $\left(\mathrm{Vm}^{-1}\right)$ & $\left(\mathrm{Vm}^{-1}\right)$ \\
\hline 0 & 70 & 95 & 115 & 85 \\
1 & 60 & 100 & 105 & 83 \\
2 & 40 & 90 & 100 & 75 \\
3 & 35 & 85 & 85 & 65 \\
4 & 40 & 83 & 70 & 60 \\
5 & 34 & 80 & 60 & 55 \\
6 & 32 & 90 & 55 & 52 \\
7 & 30 & 100 & 65 & 55 \\
8 & 50 & 150 & 80 & 75 \\
9 & 140 & 135 & 60 & 148 \\
10 & 135 & 110 & 155 & 138 \\
11 & 110 & 100 & 145 & 125 \\
12 & 75 & 95 & 125 & 100 \\
13 & 60 & 90 & 100 & 75 \\
14 & 35 & 85 & 83 & 70 \\
15 & 30 & 86 & 70 & 53 \\
16 & 30 & 90 & 72 & 55 \\
17 & 32 & 95 & 75 & 60 \\
18 & 50 & 94 & 73 & 70 \\
19 & 70 & 102 & 85 & 75 \\
20 & 85 & 103 & 100 & 95 \\
21 & 75 & 95 & 110 & 85 \\
22 & 70 & 90 & 95 & 80 \\
23 & 40 & 87 & 93 & 75
\end{tabular}

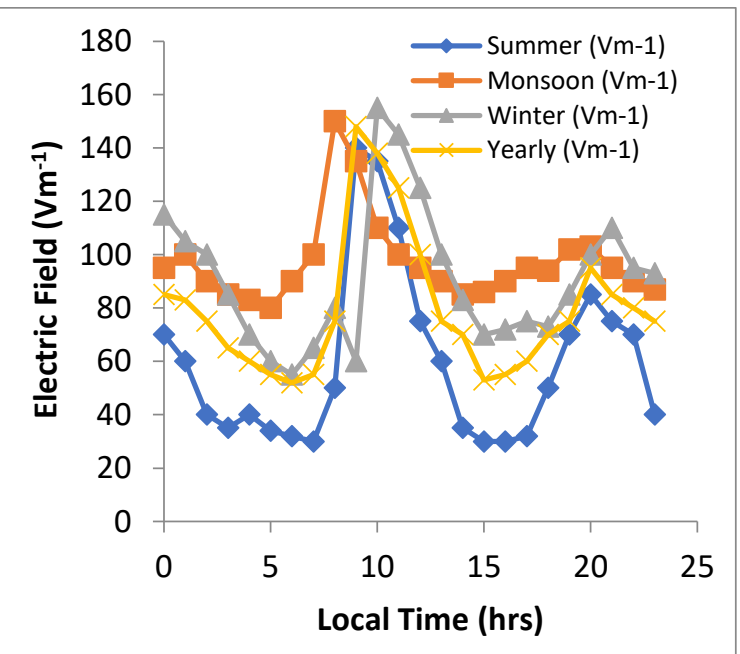

Fig 1: Daily variation of ground (EF): four seasons' (O.N.D.J. for winter, J.J.A.S. for monsoon and F.M.A.M. for summer) relationship

The result of table 2 was utilized to obtain Figure 3. The figure indicates the seasonal and annual average variability in the EF from this, it is clear that; the entire curve displays a bimodal difference with a peak at sunrise and a peak at dusk.

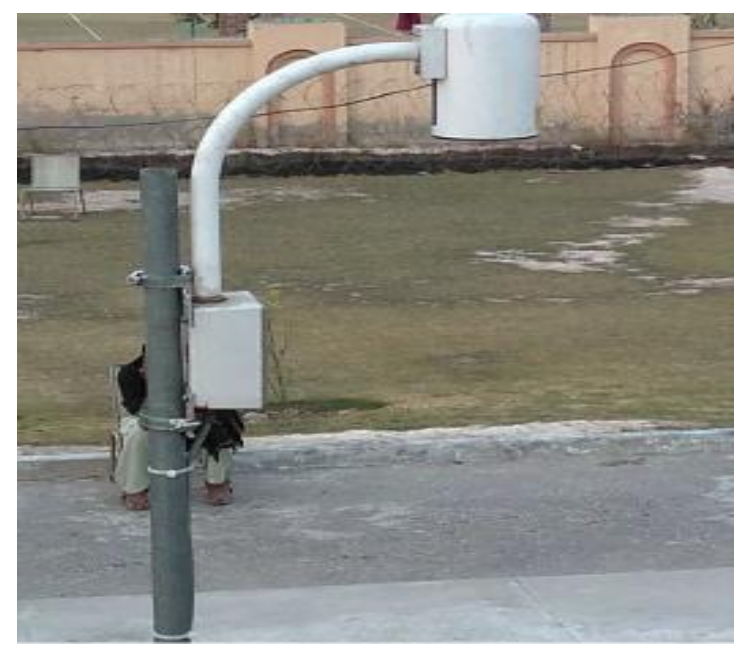

Fig 2: Electric Field Mill Sensor

Table2: Variation of Electric Field and Time on a usual day of

\begin{tabular}{llll}
\multicolumn{3}{c}{ Summer } \\
\hline $\begin{array}{l}\text { Time } \\
(\mathrm{hrs})\end{array}$ & $\begin{array}{l}\text { Electric } \\
\text { Field } \\
\left(\mathrm{Vm}^{-1}\right)\end{array}$ & $\begin{array}{l}\text { Time } \\
(\mathrm{hrs})\end{array}$ & $\begin{array}{l}\text { Electric } \\
\text { Field } \\
\left(\mathrm{Vm}^{-1}\right)\end{array}$ \\
\hline 0 & 20 & 13 & 50 \\
1 & 10 & 14 & 30 \\
2 & 45 & 15 & 25 \\
3 & 25 & 16 & 20 \\
4 & 22 & 17 & 22 \\
5 & 24 & 18 & 25 \\
6 & 15 & 19 & 10 \\
7 & 15 & 20 & 70 \\
8 & 40 & 20.5 & 72 \\
9 & 60 & 21 & 60 \\
10 & 130 & 22 & 40 \\
11 & 110 & 23 & 10 \\
12 & 80 & & \\
\hline
\end{tabular}

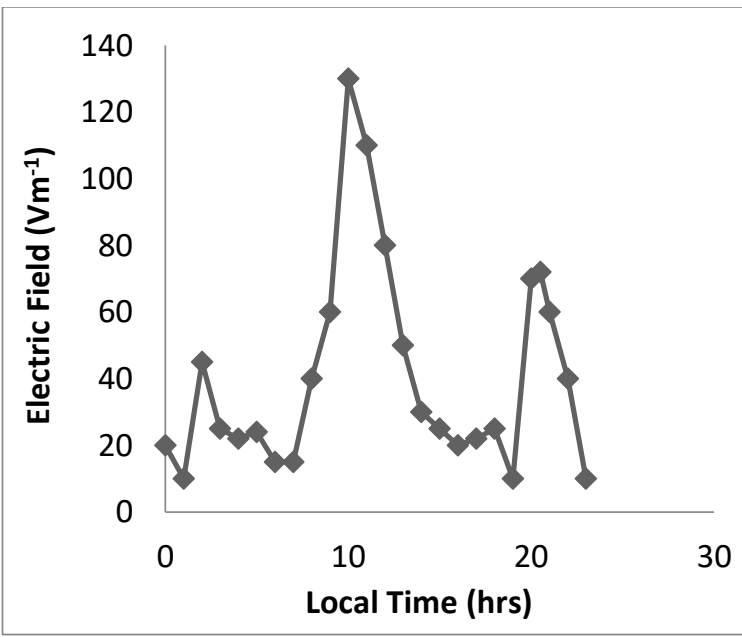

Figure 3:Variation of Electric Field on a usual day of Summer

Now viewable is Minima (early morning and afternoon). Sunrise peak happens from 6:30- 
10 hours and plateau at about $18-22$ hours in the evening. In summer and winter normal $\mathrm{E}$ curve falls between curves, the summer curve has the smallest afternoon minimum value. For the sunrise point it has the sharpest slope of rising, the heavy rain curve holds the maximum rate of electric field. Sunrise climax occurs earliest during this season and soon settle down with the daytime rate. Daylight decline with field interest is small and sunset increase isn't very obvious. The annual diurnal indicator seems to be closely followed by the winter curve. The sunrise point sets with the slowest pace during winter yet peaking at night is the sharpest and fastest of all.

\begin{tabular}{|c|c|c|c|c|}
\hline $\begin{array}{l}\text { Time } \\
\text { (hrs) }\end{array}$ & $\begin{array}{l}\text { Electric } \\
\left(\mathrm{Vm}^{-1}\right)\end{array}$ & Field & $\begin{array}{l}\text { Time } \\
(\mathrm{hrs})\end{array}$ & $\begin{array}{l}\text { Electric Field } \\
\left(\mathrm{Vm}^{-1}\right)\end{array}$ \\
\hline 0 & 110 & & 12.5 & 74 \\
\hline 1 & 105 & & 13 & 70 \\
\hline 2 & 125 & & 14 & 70 \\
\hline 3 & 85 & & 15 & 72 \\
\hline 4 & 75 & & 16 & 70 \\
\hline 5 & 70 & & 16.5 & 73 \\
\hline 6 & 80 & & 17 & 70 \\
\hline 7 & 100 & & 18 & 75 \\
\hline 8 & 180 & & 19 & 85 \\
\hline 9 & 145 & & 20 & 75 \\
\hline 9.5 & 110 & & 21 & 55 \\
\hline 10 & 95 & & 21.5 & 54 \\
\hline 11 & 75 & & 22 & 55 \\
\hline 12 & 72 & & 23 & 80 \\
\hline
\end{tabular}

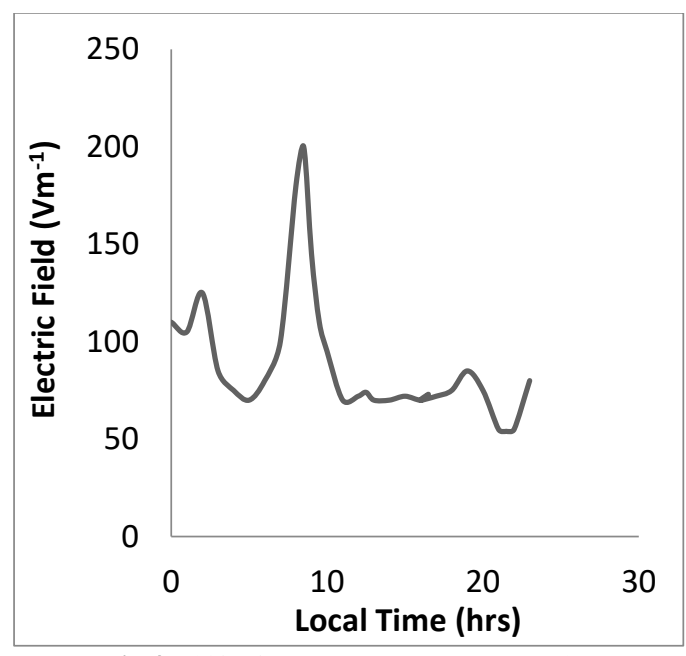

Fig 4: Shift of EF on Average Monsoon day

The graph of shift of EF on average Monsoon day is obtained from table 3. In Figure 4, our findings revealed a steady enhancement in electric field values over the days as well as a boost in the Angstrom Turbidity Coefficient the same as a pointer of enlarged pollution. It is assumed that difference in resistivity of the lesser atmospheric stratum due to different factors such as 1.0 , differences in vertical convection ions of different size ranges difference in the aerosol content influencing them and pattern of space charges due to different causes are the factors.

Table 4: Values of Disparity of EF and Time on a distinctive

\begin{tabular}{llll}
\multicolumn{4}{c}{ day of Monsoon } \\
\hline $\begin{array}{l}\text { Time } \\
(\mathrm{hrs})\end{array}$ & $\begin{array}{l}\text { Electric } \\
\text { Field }\left(\mathrm{Vm}^{-1}\right)\end{array}$ & $\begin{array}{l}\text { Time } \\
(\mathrm{hrs})\end{array}$ & $\begin{array}{l}\text { Electric } \\
\text { Field }\left(\mathrm{Vm}^{-1}\right)\end{array}$ \\
\hline 0 & 70 & 10 & 200 \\
1 & 65 & 11 & 105 \\
1.5 & 105 & 12 & 55 \\
2 & 90 & 13 & 25 \\
3 & 25 & 14 & 22 \\
4 & 55 & 15 & 20 \\
4.5 & 65 & 16 & 27 \\
5 & 60 & 17 & 45 \\
5.5 & 40 & 18 & 43 \\
6 & 35 & 19 & 70 \\
6.5 & 35 & 19.5 & 72 \\
7 & 40 & 20 & 73 \\
7.5 & 34 & 21 & 110 \\
8 & 55 & 22 & 100 \\
8.5 & 75 & 23 & 70 \\
9 & 150 & & \\
\hline
\end{tabular}

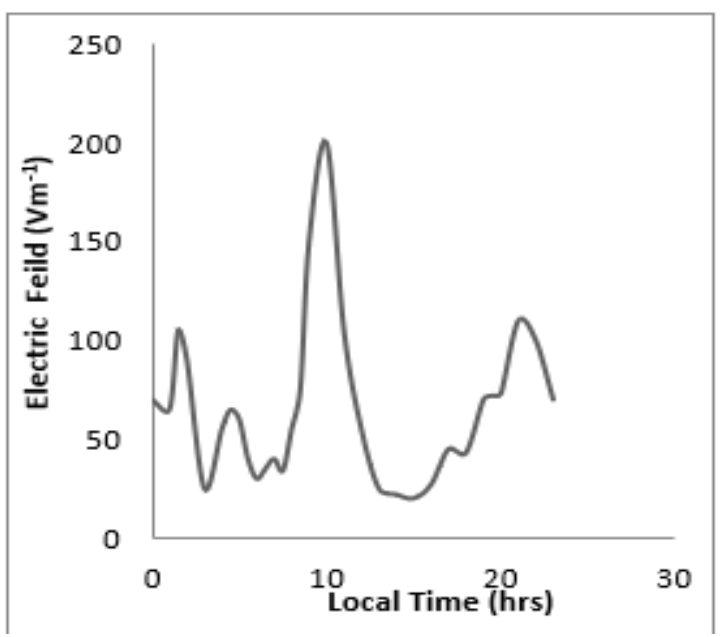

Fig 5: Disparity of EF on a distinctive day of Monsoon

The yearly variation of EF throughout a year is shown in Figure 5 using table 4. As a result of erratic rains, the field appears saturated during the monsoon season and the black soil here also retains it for a prolonged period of time. These conditions encourage fairly much evaporation in the afternoon hours. Variability of seasonal conductivity at this research station indicates no significant change in conductivity values throughout day time.

Table5: Yearly Variation of EF throughout a year

\begin{tabular}{ll} 
Seasons & Electric Field $\left(\mathrm{Vm}^{-1}\right)$ \\
\hline $1 \mathrm{~S}$ & 70 \\
$2 \mathrm{M}$ & 100 \\
$3 \mathrm{~W}$ & 90 \\
\hline
\end{tabular}

Figure 6 shows yearly variation of EF throughout a year. The amount of appreciable convection in many ground stations at higher latitudes holds the key to single oscillation. The transfer of EF to day time 
values although, the values begin to decline in the afternoon hours and the cycle is constrained due to the early temperature drop resulting in inhibition of free convection. The regular variability in aerosol charging the average conductivity drop in the months of winter at this location and this increases the EF rating. Figure 7 shows the annual variance of electric field by monthly averages; seasons: winter JD, summer FM, pre-monsoon AM, moonsoon JJAS and post-monsoon $\mathrm{ON}$. The peaks value occurs during the months of April and May and a higher value was observed in the months of October and November. While the least observed in the months of February and March respectively. Although, the monsoon era is the cleanest of all seasons, the concentration of aerosols will definitely differ during the rainy and non-rain (break) time. Since this analysis is fundamentally a fair-weather research, raining days are not incorporated and average values are valid for

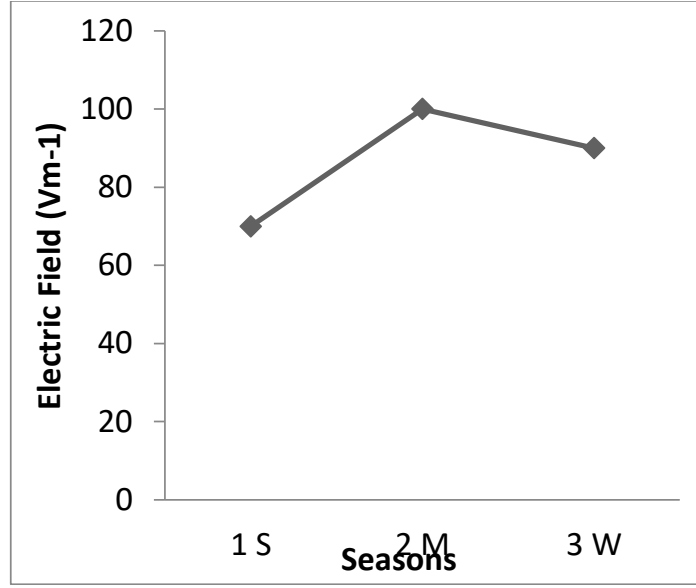

Fig 6: Yearly Variation of EF throughout a year; seasons: F.M.A.M. for Summer, J.J.A.S. for Monsoon and N.D.J.F for Winter aerosol concentration measurements

Table6: Annual Variance of Electric Field by Monthly Averages

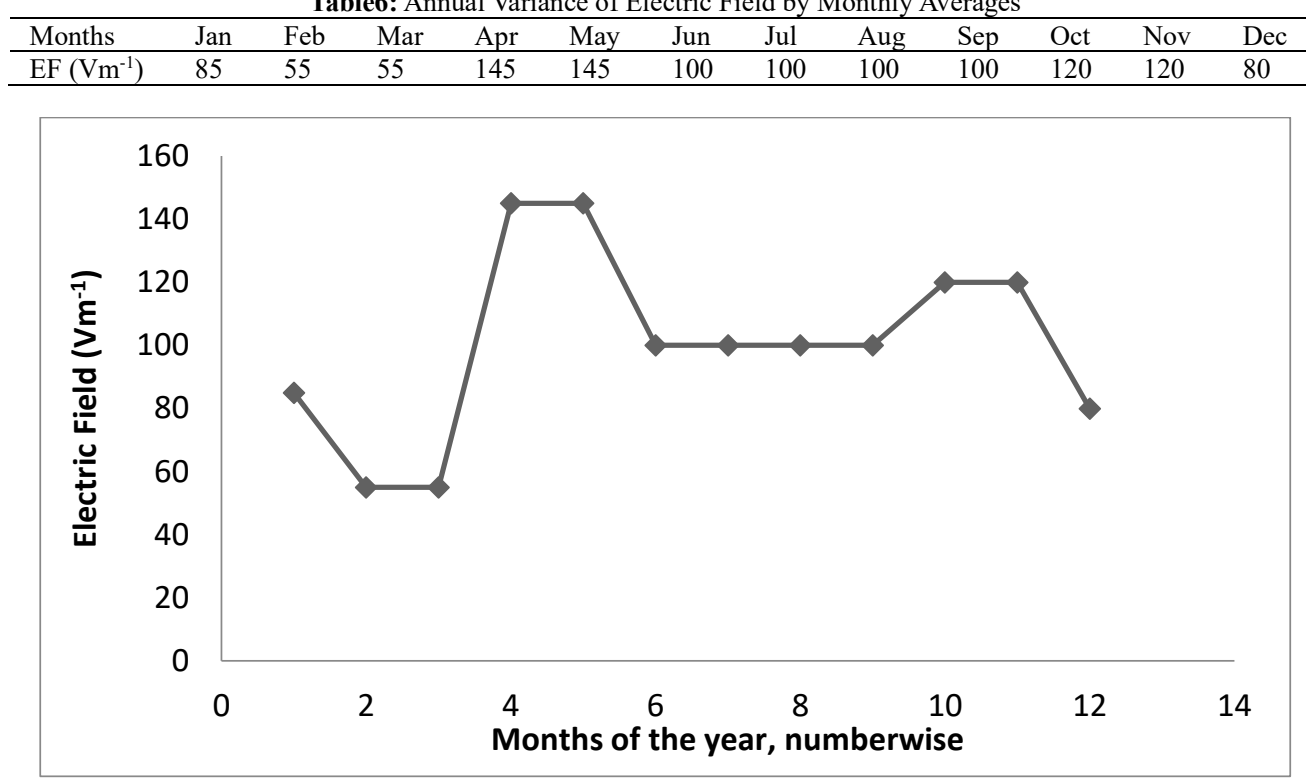

Fig 7: Annual Variance of Electric Field by Monthly Averages

Conclusion: It has been observed that the regular variability in aerosol charging the average conductivity drop in the months of winter at this location and this increases the electric field rating. The mean electric field has been found to be stronger in winter than in the other three seasons. The electric field displayed a multimodal oscillation at fair weather during the day because of the sunlight influence and the upward air convection and the conductivity at this location is characterized by pollution-related aerosol.

Acknowledgements: We acknowledge the people in charge of data collection at the Nigeria Meteorology
Station for making the data accessible.

\section{REFERENCES}

Bennett, AJ; Harrison, RG (2006a). Atmospheric electricity in different weather conditions. Weather 62: 277-283.

Chelani, AB (2013). Study of extreme $\mathrm{CO}, \mathrm{NO}_{2}$ and $\mathrm{O}_{3}$ concentrations at a traffic site in Delhi: Statistical persistence analysis and source identification. Aerosol Air Qual. Res.13: 377384. 
Ezeh, GC; Obioh IB; Asubiojo OI; Abiye OE (2012). PIXE Characterization of PM10 and PM2.5 particulates sizes collected in Ikoyi Lagos, Nigeria. Toxicol. Environ. Chem. 94(5): 884-894

Harrison, RG (2006). Urban smoke concentrations at Kew, London, 1898-2004. Atmos. Environ. 40: 3327-3332.

Harrison, RG (2004c). The global atmospheric electric circuit and climate, Surveys in Geophysics (25) $441-484$.

Ikamaise, VC; Akpan, IO; Essiett, AA; Uwah, IE (2013). Concentrations and source apportionment of total suspended particulate matter in Calabar Air basin. Int. J. Dev. Sust. 2 (2) 1203-1213.

Moses, EA; Orok; UB (2015). Contamination and health risk assessment of suspended particulate matter (SPM) in Uyo, Niger Delta, Nigeria. J. Sci. Res. P Reports 6 (4): 276-286.

Retalis, D; Retalis, A (1997). The atmospheric electric field in Athens-Greece. Meteorol. Atmos. Phys. 63: 235-241.
Ronalds, BF (2016). Sir Francis Ronalds: Father of the Electric Telegraph. London: Imperial College Press. ISBN 978-1-78326-917-4.

Ronalds, BF (June, 2016). "Sir Francis Ronalds and the Early Years of the Kew Observatory". Weather. 71(6):131-134

Rycroft M; Harrison, RG (2011). On the electrical charge of motor vehicle exhaust particles. $J$. Aerosol Sci.37: 858-874.

Turns, BF (2006). Benjamin Franklin and lightning rods. Phys. Today 59 (1), 42.

Wilson, C (1920). Investigations on lightning discharges and on the electric field of thunderstorms. Phil. Trans. Roy. Soc. Lond. A221, 73-115 